\title{
Passive seismic monitoring of potentially unstable rock masses
}

\author{
C. Colombero, C. Comina \& S. Vinciguerra \\ Dipartimento di Scienze della Terra, Università degli Studi di Torino, Torino, Italy \\ D. Jongmans, L. Baillet, A. Helmstetter, E. Larose \& J. Valentin \\ Université Grenoble Alpes, ISTerre, CNRS, Grenoble, France
}

\begin{abstract}
Passive seismic monitoring data acquired at the potentially unstable granitic cliff of Madonna del Sasso (NW Italy) are presented in this work. The spectral content of seismic noise systematically highlighted clear energy peaks on the unstable sector, interpreted as resonant frequencies of the investigated volume. Ground motion at these frequencies was found to be controlled by the main fractures observed at the site and numerical modelling is currently under development for geomechanical and modal analysis of the site. Both spectral analysis and cross-correlation of seismic noise showed seasonal reversible variations related to temperature fluctuations. No irreversible changes, resulting from serious damage processes, were detected during the monitored period. Classification and location of microseismic events had also been attempted but resulted challenging due to the complex structural and morphological setting of the cliff.
\end{abstract}

\section{INTRODUCTION}

An appropriate monitoring of unstable rock masses may provide a better knowledge of the active processes and help to forecast their evolution to failure. Classical monitoring mainly involve both remote-sensing techniques and in-situ geotechnical measurements. Although all these methods are largely applied and successfully tested on landslides, they are not suitable to early forecast sudden rapid slides or localized collapses of rocks. Passive seismic monitoring can be potentially helpful for this purpose.

Detection, classification and localization of microseismic events within the prone-to-fall rock mass can provide information about the incipient failure of internal rock bridges (Spillman et al. 2007, Lacroix and Helmstetter 2011). Acceleration to failure can be detected from an increasing microseismic event rate. The latter can be compared with meteorological data to understand the external factors controlling stability (Amitrano et al. 2010, Helmstetter \& Garambois 2009).

On the other hand, ambient vibration surveys have been recently applied to potentially-unstable rock slopes, with different geological settings and volumes, showing the capability of spectral analysis of seismic noise to detect both reversible and irreversible modifications within the rock masses. Literature studies, mostly carried out in the Alpine context (Moore et al. 2011, Burjánek et al. 2012, Bottelin et al. 2013), systematically highlighted clear energetic peaks at specific frequencies on the unstable sectors, which were interpreted as resonant frequencies of the investigated volumes. Horizontal ground motion at the fundamental frequency was moreover found to be orthogonal to the main fractures observed at the sites and consequently parallel to the potential direction of collapse. Each unstable compartment showed seasonal reversible variations of the resonant frequencies related to temperature fluctuations. In some cases, also irreversible variations were detected. Lévy et al. (2010) recorded a significant $\operatorname{drop}(>1 \mathrm{~Hz})$ in the lowest resonant frequency two weeks before the effective collapse of a limestone column.

In this framework, we discuss the monitoring data acquired at the potentially unstable cliff of Madonna del Sasso. A microseismic monitoring network was installed at the site in October 2013 for both continuous noise monitoring and detection of microseismic events related to fracturing.

\section{THE TEST SITE}

\subsection{Geographical and geological setting}

The cliff of Madonna del Sasso $\left(45^{\circ} 79^{\prime} \mathrm{N}, 8^{\circ} 37^{\prime} \mathrm{E}\right)$ is located in NW Italy, on the western shore of the Orta Lake. It is a high massive granite outcrop (Granito di Alzo ) bordered on three sides (N, E and S) by roughly vertical walls, with a height of about $200 \mathrm{~m}$ (Fig. 1). The top of the relief is located at an altitude of approximately $650 \mathrm{~m}$ a.s.l. and it is occupied by a panoramic square, in front of the XVIII-century sanctuary from which the place takes its name. At the bottom of the slope, between the cliff and the lake, there are several buildings, including houses and small factories, and 


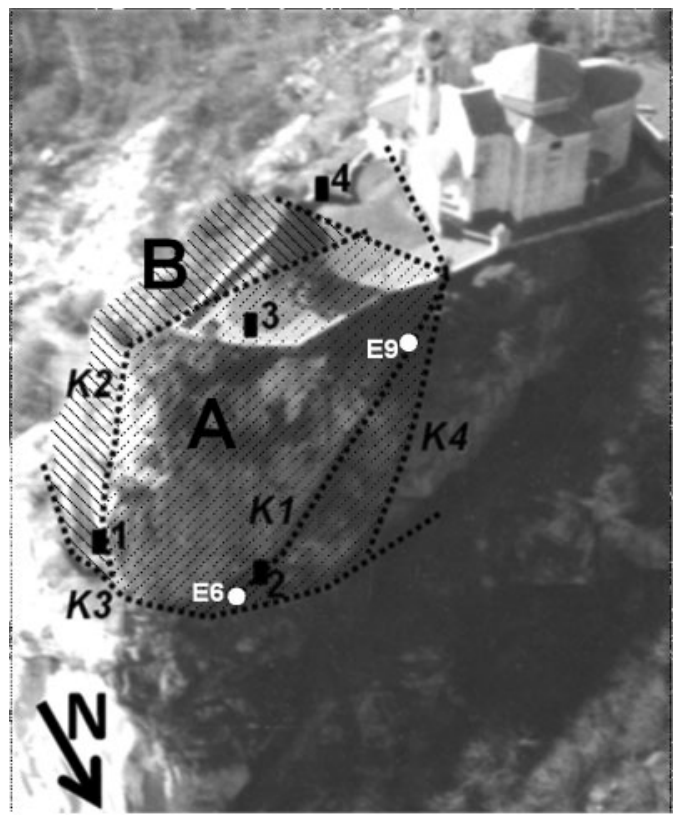

Figure 1. Aerial view of the cliff of Madonna del Sasso (VB). Dotted lines follow the traces of the main fractures affecting the site. Black numbered rectangles refer to the location of the triaxial geophones of the monitoring network. White circles are two crackmeters of the monitoring network operating from 1991 to 1992 (Regione Piemonte 1993).

the road (SP 46) connecting the towns on the western shore of the lake.

\subsection{Past monitoring}

Since 1981 warnings related to movements and crack openings on the top courtyard were reported by the municipal administration. A geomechanical characterization of the site (Lancellotta et al. 1991) led to define the rock mass as intact or massive but affected by widely spaced discontinuities characterized by good surface quality. Four main joint sets were identified (dip direction/dip): K1 (110/75), K2 (0/80), K3 (150/15) and K4 (50/75). These discontinuities (Fig. 1) tend to isolate two frontal portions of the cliff which increase their instability depending upon the rock bridges present along the fractures and the foot edge. A volume of about $12,000 \mathrm{~m}^{3}$ has been estimated forming the most instable sector at the north-eastern limit of the cliff, bordered by fractures $\mathrm{K} 2$ and $\mathrm{K} 4$ (or $\mathrm{K} 1$ ) on the sides and probably truncated at the bottom by K3 system (sector A in Fig. 1). South to this sector, a second block was identified (sector B in Fig. 1), delimited by fractures $\mathrm{K} 4$ and $\mathrm{K} 2$ on the sides and $\mathrm{K} 3$ at the base, with a volume of about $7,500 \mathrm{~m}^{3}$. Particularly along K4 discontinuity there is a clear evidence of displacement: a visible decimetric step dislocates the lawn and the confining walls of the panoramic square. On the other hand, K2 fracture seems to show the widest opening (around $40 \mathrm{~cm}$ ) with a significant

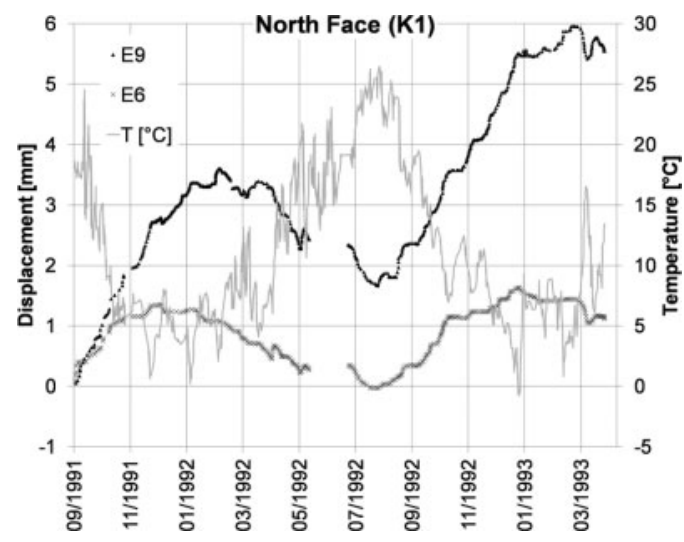

Figure 2. Monitoring with crackmeters at different elevations along K1 fracture: E6 at the base and E9 close to the top of sector A (Regione Piemonte 1993).

persistence within the rock mass and apparently no filling material for the first meters of observation.

From 1991 to 1992 , a network of 10 automatic crackmeters coupled with temperature probes was installed for the displacement monitoring of sector A. Five sensors were deployed on the northern side, following $\mathrm{K} 1$ fracture, and the other were placed on the southern cliff along $\mathrm{K} 2$ fracture, at different elevations. The resulting data (Fig. 2) suggested that the joint opening is inversely connected to the mean air temperature and displacements are interpreted as the outcome of rock-mass thermal contraction, with a maximum opening in winter, and a minimum opening in summer, related to thermal expansion. This positive and negative peaks are followed by a gradual closing (in spring) and opening (in autumn) trend. At the end of an annual cycle of observation three probes went back to the initial zero-value while 7 sensors preserved a residual opening of an average of $2 \mathrm{~mm} /$ year. A differential behaviour in the displacement curves was also detected: the maximum opening values were recorded at the highest probes (5-6.1 mm/year, i.e. E9 in Fig. 2), suggesting a foot control on the displacements of sector A (Regione Piemonte 1993).

\subsection{The microseismic monitoring network}

The microseismic network is operating at Madonna del Sasso from the end of October 2013. It consists of four triaxial geophones $(4.5 \mathrm{~Hz}, 1-4$ in Fig. 1) connected to a multichannel acquisition system (Granite - Kinemetrics). The first two geophones are placed on sheltered areas of the high walls of the cliff, at a height of about $45 \mathrm{~m}$ below the top yard, on the south-eastern (station 1) and northern (station 2) side of the unstable volume. The other two stations ( 3 and 4 ) are located in shallow manholes accessible from the panoramic square, with station 3 on top of the unstable volume and station 4 supposed to be outside the prone-to-fall part of the cliff (reference station). The network is planned to operate with both a continuous mode for seismic 
noise registration (250-Hz sampling frequency) and a trigger recording based on a STA/LTA algorithm for the detection of microseismic events $(1-\mathrm{kHz}$ sampling frequency).

\section{SEISMIC NOISE}

\subsection{Spectral analysis}

The spectral content of ambient seismic noise recorded on the prone-to-fall compartment (stations 1, 2 and 3) exhibits clear peaks at specific frequencies and orientations. In contrast, no significant peaks in amplitude and directionality were observed in the data for the stable rock mass (station 4 ).

The Probability Density Function (PDF) of the spectral ratios between the horizontal and vertical component of ambient seismic noise (4200 hourlasting recordings acquired from October 2013 to August 2014) was computed for each station and between the same component of a station placed in the prone-to-fall compartment and the stable one (V/V4, $\mathrm{N} / \mathrm{N} 4$ or E/E4). Hereafter results are shown for the station at the top of the unstable sector (station 3), but similar results can be observed also for the other unstable stations. In Figure 3, the PDF of the computed $\mathrm{H} 3 / \mathrm{V} 3$ spectral ratios are reported. The PDF exhibits a first clear peak around $2.7 \mathrm{~Hz}$, followed by a second lower one at $5.5 \mathrm{~Hz}$ and a third one centred around $4 \mathrm{~Hz}$. These three values are interpreted as the natural frequencies of the unstable volume. The observed resonant frequency is below the natural frequency of the adopted geophones which could show limited low-frequency capability depending on their sensitivity $(44 \mathrm{~V} / \mathrm{m} / \mathrm{s}$ for our instrumentation). However, independent data acquired with lower-frequency sensor (2s) in two days of recording (25-26 November 2010) confirm the observed frequency values (Bottelin 2014).

Especially for the first resonance peak, the evolution of spectral ratios with time (Fig. 4) suggests a slow fluctuation from $2.6 \mathrm{~Hz}$ to $3.1 \mathrm{~Hz}$ during the monitored period. These fluctuations may reflect the thermal control on the stability of the cliff as observed by crackmeters and commented later.

In Figure 5 the azimuthal plot (Fig. 5a) and the stereographic projection (Fig. 5b) of the orientation of noise spectral content are shown in comparison with a simplified planar view of the main fractures affecting the site (Fig. 5c). Azimuths are displayed clockwise from $\mathrm{N}$, in the $1-10 \mathrm{~Hz}$ range (radial direction of the circle, Fig. 5a). The motion of the predominant vibrations appear to be controlled by the orientation of the main discontinuities separating the unstable compartment from the intact rock. Given the complex fracture setting of the site, in order to validate the data interpretation and associate to each frequency value the related vibration mode (lateral/transverse bending or torsion), 3-D numerical modeling of the cliff response is currently under investigation using the

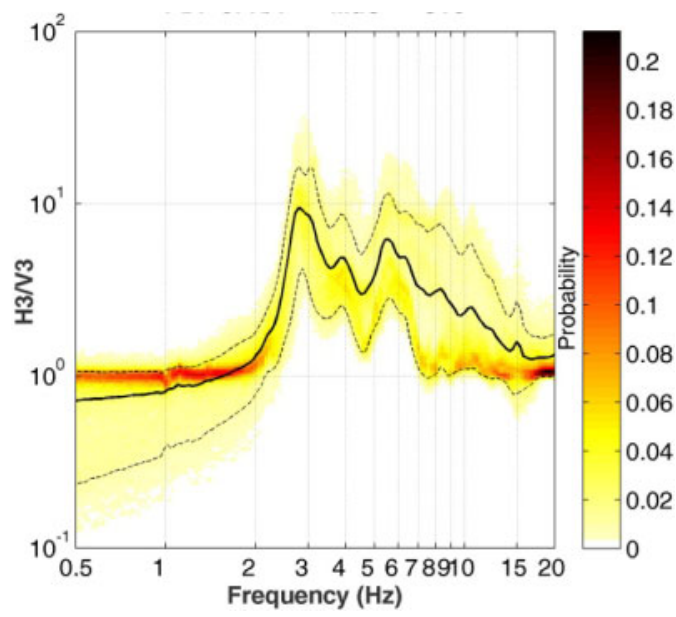

Figure 3. Probability Density Function of the computed $\mathrm{H} / \mathrm{V}$ spectral ratios for station 3 (October 2013 - August 2014). The bold and the dashed lines are respectively the mean and the $25^{\text {th }}$ and $75^{\text {th }}$ percentiles of the whole dataset.

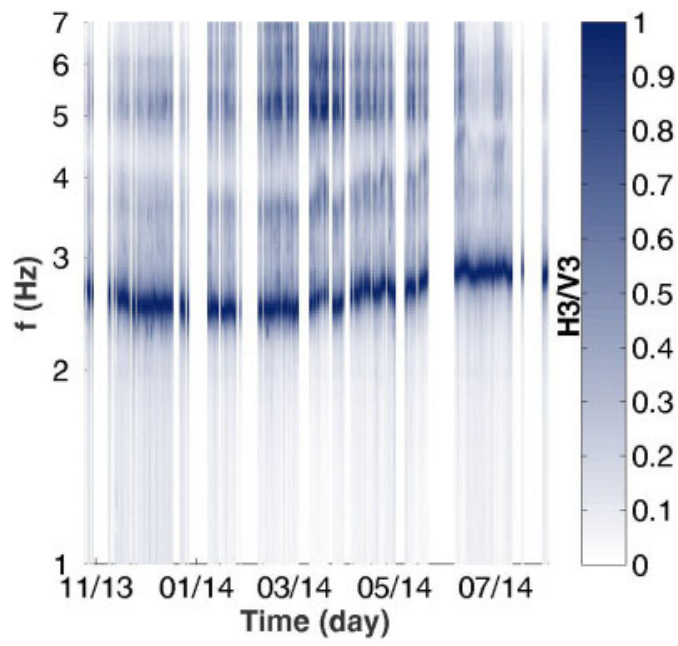

Figure 4. Fluctuation of the H3/V3 spectral ratio with time; each spectrum is normalized to its maximum value.

continuous-medium finite-element software Comsol Multiphysics.

\subsection{Cross-correlation}

In order to monitor the variations of the seismic properties inside the rock mass the cross-correlation between the recordings of all the couples of sensors over the whole monitored period was computed. Analyses were focused in the 2 to $20 \mathrm{~Hz}$ frequency band, which roughly corresponds to a progressively reducing penetration depth of seismic waves.

Before computing the correlation, the data of each station were prepared following the same preprocessing procedure, involving spectral whitening and clipping. 


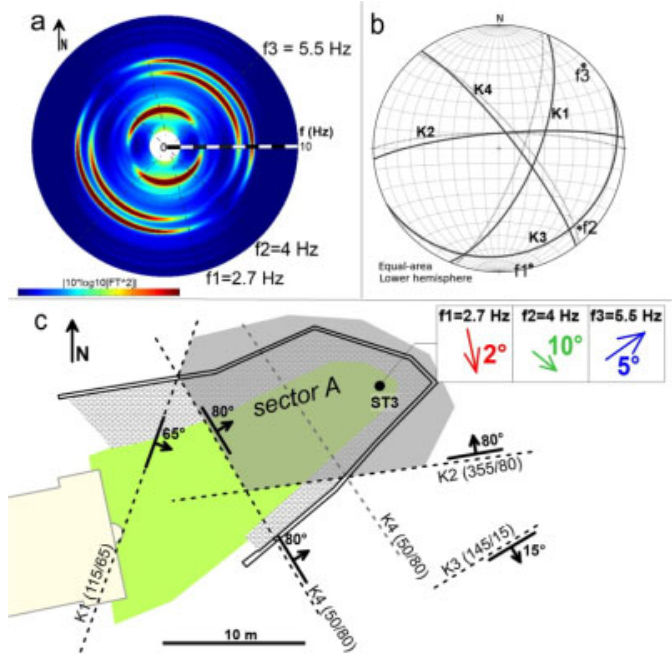

Figure 5. (a) Polar plot (horizontal plane, with $\mathrm{N}$ on the vertical direction) of the spectral peaks of seismic noise for the horizontal components of station 3. (b) Stereographic projection of the 3-D orientation of the identified first three natural frequencies $(\mathrm{f} 1=2.7 \mathrm{~Hz}, \mathrm{f} 2=4 \mathrm{~Hz}$ and $\mathrm{f} 3=5.5 \mathrm{~Hz}$ ) plotted in comparison with the orientation of the fracture planes. Dashed lines refers to the orientations identified by Lancellotta et al. (1991), bold lines are the recalculated orientation obtained with a non-contact geomechanical survey on oriented photos of the cliff associated to a laser-scanner point cloud (software AdHoc). (c) Simplified planar view of the site with fracture locations and orientations.

Correlograms were then hourly calculated for each couple of stations and averaged to obtain 24-hour correlations, ensuring more stable correlation with time. Both hourly and daily correlograms were used, in order to focus both on short-time changes (daily variations) and on long-time fluctuations (seasonal variations). Correlograms were filtered at subsequent central frequencies from $3 \mathrm{~Hz}$ to $13 \mathrm{~Hz}$, with a $2 \mathrm{~Hz}$ bandwidth. A progressive loss in correlation between the sensors was observed when increasing the central frequency of the band.

Under the assumption of a homogeneous velocity change $\mathrm{dV}$, all the waveforms recorded after the velocity change are expected to be shifted in time by a factor $\mathrm{dV} / \mathrm{V}$. To measure this relative velocity change, the stretching method (Sens-Schönfelder \& Wegler 2006) was applied. This technique consists in testing several possible changes of the factor $\mathrm{dV} / \mathrm{V}$ by resampling the correlograms in time and choosing the one which maximizes the correlation coefficient CC (Mainsant et al. 2012). The intervals $[-2 \mathrm{~s}-0.5 \mathrm{~s}]$ and $[0.5 \mathrm{~s} 2 \mathrm{~s}]$ of each correlogram were employed in the computation, thus focusing on coda waves, essentially made up of surface waves.

As the vertical components of the four sensors were highly noise-affected and not correctly working over the whole period, all the computations were made on the horizontal components $(\mathrm{E}$ and $\mathrm{N})$. The relative phase velocity changes and values of the
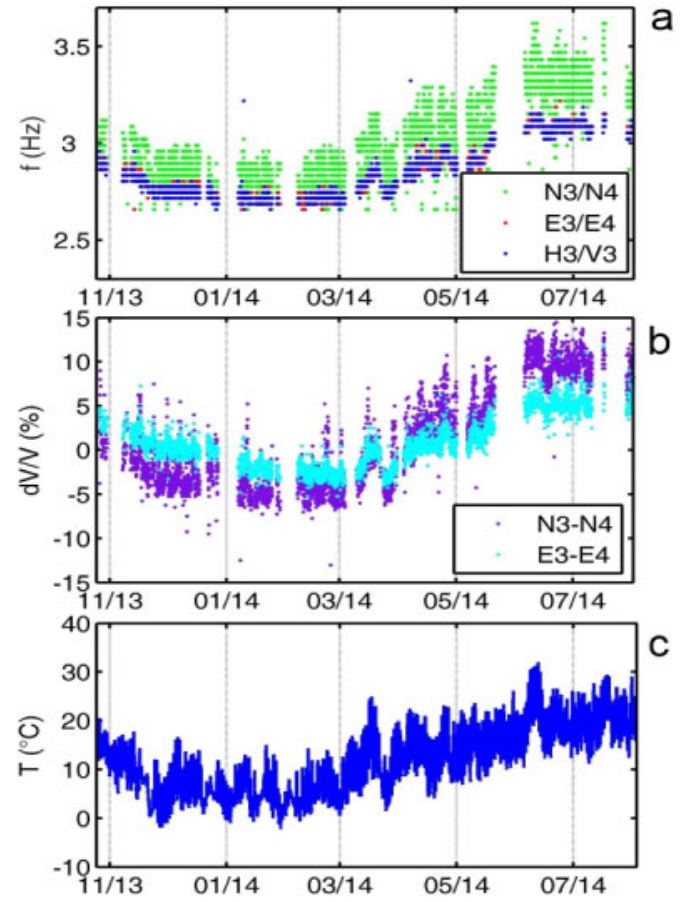

Figure 6. (a) Variations of the first resonant frequency obtained from the spectral ratios N3/N4, E3/E4 and H3/V3. (b) Cross-correlation results between stations 3 and 4 in the frequency band 2-4 Hz obtained from hour correlograms of the $\mathrm{N}$ and $\mathrm{E}$ components. Only velocity variations corresponding to $\mathrm{CC}>0.85$ are shown. (c) Air Temperature $\left({ }^{\circ} \mathrm{C}\right)$ at the site during the monitored period.

correlation coefficient were computed for each frequency band with reference to the mean of the analyzed correlograms. The most significant $\mathrm{dV} / \mathrm{V}$ was found in the 2-to-4-Hz band (around the resonant frequency of $3 \mathrm{~Hz}$ ) with variations up to $12 \%$ in the considered period and it is plotted in Figure $6 \mathrm{~b}$ in a direct comparison with previously-discussed spectral results (Fig. 6a) and temperature data recorded at the site (Fig. 6c). Both the temporal variations of the resonant frequencies, obtained from the spectral analysis, and the cross-correlation of seismic noise in the lower frequency bands suggest a reversible seasonal cycle strongly controlled by temperature fluctuations, confirming past monitoring outcomes. Increasing the frequency of analysis, the fluctuations of $\mathrm{dV} / \mathrm{V}$ reduced up to show no variations with time, in parallel with a decrease in the values of the correlation coefficients.

\section{EVENT DETECTION AND CLASSIFICATION}

During the monitored period, we recorded thousands of events with different waveforms, duration and frequency content. Our first aim was to analyze and classify these signals and to extract only the ones with a possible relation with fracture processes, since their 
source localization and time evolution can give important information with respect to the most active zones in the rock mass and their progression to failure.

Only after this classification the spatial localization and temporal distribution of the microseismic events could be used as an objective element to realize an early warning system. In order to achieve this goal, the classification of the recorded events should be done as close to real time as possible, with automatic procedures of analysis.

We preliminarily analyzed the recorded events characterizing them in time and frequency domains (Fig. 7), in order to identify the key parameters on which make reliable distinctions among the nature of each signal. The considered parameters are signal shape (in terms of amplitude, duration, kurtosis) and frequency content (range of maximum frequency content, frequency distribution in the spectrogram). As a first result, we can clearly distinguish four main classes of recorded signals: regional earthquakes (Fig. 7a, b), probable microseismic events (Fig. 7c, d), still unclassified events (probably grouping rockfalls, quarry blasts, other anthropic and natural sources, Fig. 7e, f) and electronic disturbances (Fig. $7 \mathrm{~g}, \mathrm{~h}$ ).

Possible microseismic events (Fig. 7c, d) give rise to impulsive and short duration signals which envelope has a triangle shape with a clear coda. The spectrogram has a specific aspect with a sharp energy increase followed by an exponential decay of the high-frequency content with time. They show very short duration $(0.8-4 \mathrm{~s})$ and very high kurtosis values $(>10)$. These features are in good agreement with those reported by several authors (Burlini et al. 2007, Helmstetter and Garambois 2010, Levy et al. 2011).

Regional earthquakes (Fig. 7 a, b) show lemonshape envelope and long duration (30-60 s). Most of them are characterized by quite well separated impulsive $\mathrm{P}$ - and $\mathrm{S}$-wave onsets. Their kurtosis values are always lower than 10 . The maximum energy content is in the frequency range between 1 and $20 \mathrm{~Hz}$, depending on the epicentral distance.

Noise transients generated by electrical disturbances (Fig. 7g, h) are impulsive spike-like signals, with very short duration and high-frequency energy content $(50-100 \mathrm{~Hz})$. They are probably caused by atmospheric electrical discharges and other electrical disturbances due to the length of the connecting cables between the stations and the acquisition instrument, according with what observed by Spillman et al. (2007). Not by chance, most of this type of signals affect only station 1 and, in smaller amounts, station 2 which are located on the cliff walls with connection cables of more than 50-meters length.

At the current state, determining the hypocenter locations of these possible microseismic events has revealed challenging for several reasons: the poor number of station (only 4) offers a reduced spatial coverage; many recordings are very noisy and first arrival time picking is inaccurate for some stations; there is no clear evidence of separated $p$ and s onsets in the signals; even if we are monitoring a small
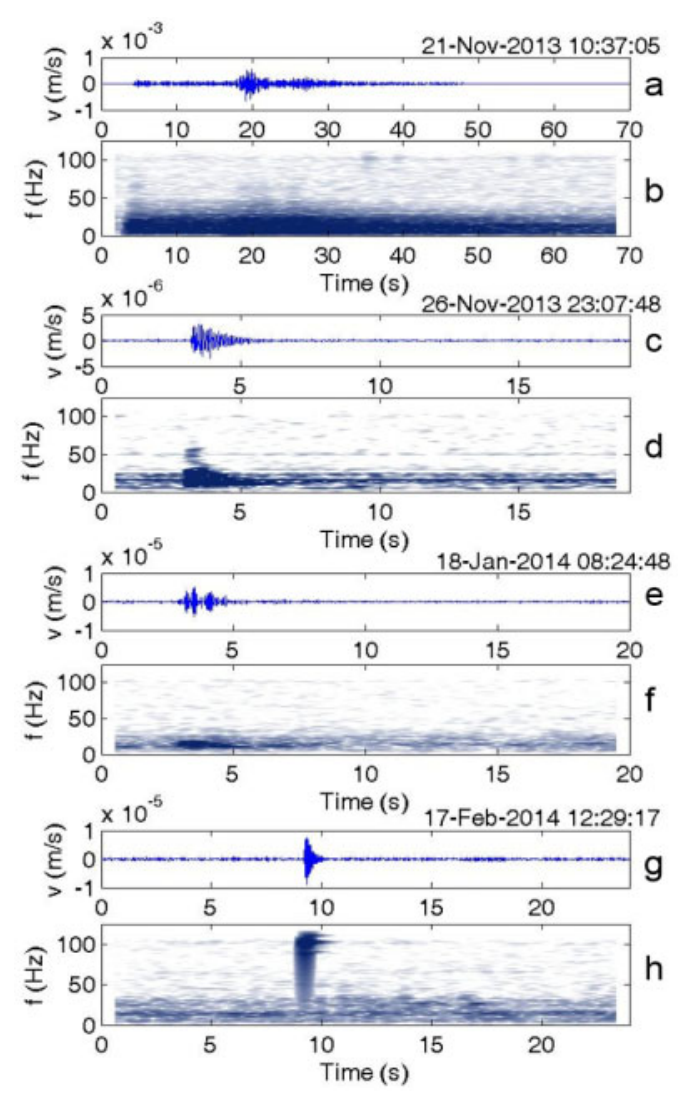

Figure 7. Selection of different types of signals. Seismograms recorded for channel E-W of ST2 (a, c, e, g) for a regional earthquake, a possible microseismic event, an unclassified event and an electronic disturbance respectively. Spectrograms of the same signals with common linear color scale (b, d, f, h).

volume, the seismic velocity inside the rock mass is highly heterogeneous due to fracturing. Scattering effects, attenuation and topographical amplification contribute to make the analysis worse.

Despite these considerations, the majority of these signals shows higher amplitude and frequency content at station 2, at the northern foot of the cliff, perhaps indicating a greater proximity of this station to the triggering source. No acceleration in the event rate or significant correlation with variations of external factors (air temperature, rainfalls) was detected in the monitored period.

\section{CONCLUSIONS}

Passive seismic monitoring techniques revealed a valid tool to analyze the instability of Madonna del Sasso. Working on seismic noise, both the temporal variations of the resonant frequencies and cross-correlation results suggest a reversible seasonal cycle strongly controlled by temperature fluctuations, as already 
highlighted by past conventional monitoring with direct measurements of displacement across the fractures. Thermal contraction of the rock mass during cold months results in a decrease of the resonant frequency and in the seismic velocity field, probably linked with a major opening of fractures, while a maximum in the resonant frequency and an increase in velocity are observed in summer due to fracture closing, as a result of thermal expansion. No irreversible changes, resulting from damage processes in the rock mass, were detected during the monitored period. Modal analysis and thermal modelling are under development, to identify the modes related to the resonant frequencies detected at the site, while classification and location of microseismic events is still the most challenging task, due to the complex structural and morphological setting of the site.

\section{REFERENCES}

Amitrano, D., Arattano, M., Chiarle, M., Mortara, G., Occhiena, C., Pirulli, M. \& Scavia, C. 2010. Microseismic activity analysis for the study of the rupture mechanisms in unstable rock masses. Nat. Hazards Earth Syst. Sci., 10, 831-841.

Bottelin, P., Jongmans, D., Baillet, L., Lebourg, T., Hantz, D., Lévy, C., Le Roux, O., Cadet, H., Lorier, L., Rouiller, J.-D., Turpin, J. \& Darras, L. 2013. Spectral Analysis of Proneto-fall Rock Compartments using Ambient Vibrations. $J$. Environ. Eng. Geophys., 18: 205-217.

Bottelin, P. 2014. Charactérisation des phases pré-et postrupture d'éboulements rocheux de taille intermédiaire: Apport des enregistrements sismiques. Phd thesis. ISTerre - Université de Grenoble. HAL Id: tel-01162605.

Burjánek, J., Moore, J.R., Yugsi Molina, F.X. \& Fäh, D 2012. Instrumental evidence of normal mode rock slope vibration. Geophys. J. Int., 188 (2): 559-569.

Burlini, L., Vinciguerra, S., Di Toro, G., De Natale, G. \& Burg, J.-P. 2007. Seismicity preceding volcanic eruptions: new experimental insights. Geology, 35 (2): 183-186.
Helmstetter, A. \& Garambois, S. 2010. Seismic monitoring of Séchilienne Rockslide (French Alps): analysis of seismic signals and their correlation with rainfalls, J. Geophys. Res., 115, F03016, doi:10.1029/2009JF001532

Lacroix, P. \& Helmstetter A. 2011. Localization of seismic signals associated with micro-earthquakes and rockfalls on the Séchilienne landslide, French Alps, Bull. Seism. Soc. Am. 101(1): 341-353, doi: 10.1785/0120100110

Lancellotta, R., Gigli, P. \& Pepe, C. 1991. Relazione tecnica riguardante la caratterizzazione geologico-strutturale dell'ammasso roccioso e le condizioni di stabilità della rupe. Private communication.

Lévy, C., Baillet, L., Jongmans, D., Mourot, P. \& Hantz, D. 2010. Dynamic response of the Chamousset rock column (Western Alps, France). J. Geophys. Res., 115, F04043, 13 pp., doi: 10.1029/2009JF001606.

Levy, C., Jongmans, D. \& Baillet, L. 2011. Analysis of seismic signals recorded on a prone-to-fall rock column (Vercors massif, French Alps). Geophys. J. Int., 186: 296-310.

Mainsant, G., Larose, E., Brönnimann, C., Jongmans, D., Michoud, C. \& Jaboyedoff, M. 2012. Ambient seismic noise monitoring of a clay landslide: Toward failure prediction. J. Geophys. Res., 117, F01030, 1-12, doi:10.1029/2011JF002159.

Moore, J.R., Gischig, V., Burjánek, J., Loew, S. \& Fäh, D. 2011. Site Effects in Unstable Rock Slopes: Dynamic Behavior of the Randa Instability (Switzerland). Bull. Seism. Soc. Am., 101 (6): 3110-3116.

Regione Piemonte 1993. La rete di controllo della rupe di Madonna del Sasso, sintesi dei risultati dei primi 18 mesi di misure. Assessorato Difesa del Suolo e Governo Risorse Idriche. Settore per la prevenzione del rischio geologico, meteorologico e sismico. 1-52.

Sens-Schönfelder, C., \& Wegler, U. 2006. Passive image interferometry and seasonal variations of seismic velocities at Merapi Volcano, Indonesia. Geophys. Res. Lett., 33, L21302, doi:10.1029/2006GL027797.

Spillmann, T., Maurer, H., Green, A.G., Heincke, B., Willenberg, H. \& S. Husen S. 2007. Microseismic investigation of an unstable mountain slope in the Swiss Alps, J. Geophys. Res., 112, B07301, doi:10.1029/2006 JB004723. 